\title{
ДЕСТРУКТИВНОЕ ВЛИЯНИЕ ТЕНЕВОЙ ЭКОНОМИКИ НА НАЛОГОВУЮ СОСТАВЛЯЮЩУЮ БЮДЖЕТА И ОЦЕНКА ВОЗМОЖНЫХ ПУТЕЙ СНИЖЕНИЯ ЕЕ МАСШТАБОВ В РФ
}

\begin{abstract}
Аннотация. Предметом данного исследования выступает совокупность теоретических, методических и практических вопросов, направленных на выявление путей снижения масштабов теневой экономики как важного налогового ресурса роста бюджетных доходов и обеспечения безопасности Российской Федерации на современном этапе. Объект исследования - теневая экономическая деятельность и механизм его влияния налоговую составляющую бюджетной системы РФ. Основная цель исследования состояла в анализе масштабов негативного влияния теневой деятельности на налоговую составляющую бюджетной системы РФ и в оценке возможных путей ее снижения. $B$ процессе исследования и анализа информационно- статистического материала применялись экономико-статистические методы (обобщение, группировка, сравнения, факторный анализ и др.), приемы и принципами системного и комплексного подхода. Научная новизна работы заключается в обосновании комплекса научно-практических рекомендаций, направленных на создание институциональных условий для развития личных интересов субъектов экономики в рамках легальной деятельности, ориентированных на снижение масштабов деструктивного влияния теневой экономики на налоговую безопасность, противодействия налоговым правонарушениям как важного бюджетного ресурса РФ. В результате исследования автором дана оценка деструктивного влияния теневой экономической деятельности на налоговую составляющую доходов бюджетной системы. Показано, что в основе объективно существующих причин теневой экономики лежит нарушение личных экономических интересов субъектов предпринимательства. Аргументировано, что важную роль в снижении масштабов теневой экономики, должны играть не только действия правоохранительных и налоговых органов, но и саморазвитие, конструирование неформальных институтов, отрицающих теневую экономику. Предложено оценивать эффективность налоговой политики коэффициентом налоговой безопасности. Обозначены направления совершенствования способов взаимодействия правоохранительных и налоговых органов с другими органами исполнительной власти за движением собственности и доходов. Выделены пути создания системы государственной поддержки инвестирования в легальную экономику как фактора «обеления» неформальной экономики.
\end{abstract}

ключевые слова: деструктивное влияние, масштабы, последствия, факторы, методы оценки, налоговые потери, налоговое администрирование, пути снижения, налоговая составляющая, субъекты хозяйствования.

Abstract. The subject of this research is a set of theoretical, methodological and practical issues aimed at identifying ways to reduce the scale of the shadow economy as an important resource tax budget revenue growth and security of the Russian Federation at the present stage. The object of study is the shadow economic activity and the mechanism of its influence on the tax component of the budget system. The main objective of the study is to analyze the extent of the negative impact of shadow activity on the development of the economy and the tax component of the budget and to evaluate possible ways to reduce the size of the shadow ecnomy in the Russian Federation. In the process of research and analysis of information and statistical data the author has used economic statistical methods (generalization, grouping, comparison, factor analysis, etc..), methods and principles of systems and integrated approaches. The scientific novelty of the research is caused by the fact that the author provides a substantiation of a set of theoretical and practical recommendations aimed at creating institutional conditions for the development of personal interests of economic entities within the framework of legal activities reducing the extent of the destructive effect of the shadow economy on tax security countering tax violations as an important budgetary resources of the Russian Federation. As a result of research the author has assessed the destructive effect of the shadow economic activity on the tax revenue component of the budget system. It is shown that the basis of the objectively existing causes of the shadow economy is a violation of personal economic interests of businesses. It is also reasoned that an important role in reducing the size of the shadow economy is played not only by actions of law enforcement and tax authoritie but also self-education and creatino of informal institutions that deny the shadow economy. The author suggests that we should evaluate the effectiveness of tax policy based on the security tax ratio. The author also outlines ways to improve 


\section{Налоговое администрирование}

methods of interaction between law enforcement/tax authorities and other executive bodies in order to control the movement of property and income. The author also describes ways to create the system of state support for investment in legal economy as a factor of "whitewashing" the informal economy.

Keywords: tax component, ways to reduce, tax administration, tax loss, evaluation methods, factors, consequences, scale, destructive effect, business entities.

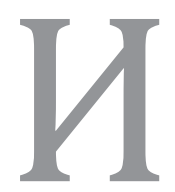

нституциональным условием успешной реализации проводимых в государстве реформ, достижения и сохранения экономической стабильности является устойчивое состояние государственных финансов, и в первую очередь эффективность налогового процесса. Сложившаяся на современном этапе экономическая ситуация, связанная с нестабильностью мировой экономики в целом и финансовой системы в частности, а также с непредсказуемостью цен на энергетические ресурсы предполагает возникновение сложностей в процессе формирования доходов бюджетной системы Российской Федерации. В современных условиях исчерпан потенциал роста налоговых поступлений за счет повышения налоговых ставок. В этих условиях важный путь повышения собираемости налогов - создание институциональных условий для снижения масштабов теневой экономики и вовлечения в процесс налогообложения неучтенных объектов налогообложения. Основную часть теневой экономики занимает деятельность, сопровождающая уклонением от уплаты налогов. Это дает основание рассматривать размеры теневой экономики как качественный индикатор уровня уклонения от налогов. Объективная оценка масштабов теневой экономики, выявление причин ее деструктивного влияния на развитие экономики, масштабность налоговых потерь доходов бюджетной составляющей и анализ путей ее снижения являются одними из ключевых проблем в отечественной практике, важной задачей, решение которой необходимо для разработки мероприятий по возвращению теневой деятельности в легальное русло и на этой основе роста налоговых поступлений в бюджеты разных уровней.

Среди исследователей существует множество трактовок понятия «теневая экономика». Несмотря на множество трактовок, наиболее лаконичным следуют считать подход, основанный на рассмотрение теневой экономики, как «сово- купность видов деятельности, дающих рыночный доход, который не декларируется» [5]. Среди работ 20 века, проблемы теневой экономики наиболее обстоятельно были исследованы, в статье американского ученого П. Гутмана «Подпольная экономика» [5]. В последующем вопросы теневой экономики рассматриваются в работах таких зарубежных ученых, как: Б. Контини, К. Моррис, В. Танзи, Х. Петерсон и многих др.

Изучение теневых экономических отношений в странах социалистического пространства начинает активно развиваться с 1980-х гг., после работы А. Каценелинбойгена [9]. Значительный вклад в исследования проблем теневой экономики внесли такие ученые, как: В. Исправников, С. Меншиков, А. Крылов, Ю. Корчагин,С. Головнин, Н. Бокун, А. Пономаренко, П. Ореховский, и др. В своих работах они дают определение понятия «теневая экономика», выделяют различные ее сектора (теневой, неформальный, черный и т.п.). Однако, не смотря на многочисленные исследования вопросов теневой составляющей экономики, наблюдающий на современном этапе рост ее масштабов и деструктивное влияние как на политическую, так и на экономическую составляющую государства обуславливают необходимость продолжения исследований в данной области. Особую актуальность имеют исследования, направленные на поиск путей легализации теневых доходов как важного источника роста налоговых доходов бюджетной системы. Следует отметить, что изучение теневой хозяйственной деятельности как своеобразной составляющей экономической активности долгое время велось в отрыве от изучения проблем обеспечения экономической безопасности государства и ее субъектов.

С течением времени в жизни общества начал отражаться в научной литературе новый подход к изучения роли теневой экономики. Один из подходов отражен в работе американского экономиста М. Олсана [9], который трактует го- 


\section{Налоги и налогообложение 10(148) • 2016}

сударство как «оседлого бандита», рассматривая тем самым преступную деятельность как органический элемент процессов полито генеза. Среди отечественных исследователей В.В. Волков рассматривает теневую экономику как органический элемент хозяйственной жизни [4], С.Ю. Барсуков, как ключевой компонент теневых механизмов политической жизни [2]. На взгляд автора, минусы теневой деятельности настолько масштабны и очевидны (нарушение рыночной мотивации деятельности хозяйствующих субъектов из-за снижения конкурентоспособности товаров, производимых законопослушным субъектом хозяйствования, снижения уровня поступлений в бюджет, рост социальной напряженности в обществе, возникновения неконтролируемых государством источников финансирования, в том числе экстремисткой направленности и др.), что перекрывают возможные ее позитивы.

Современные исследования подтверждают, что степень воздействия теневого сектора на социально-экономические отношения ослабевает по мере развития экономики [3]. Развитые индустриальные страны Европейского Союза, а также США, имеют сравнительно низкий уровень теневой экономики (в среднем, не превышающем 17\% ВВП). У стран СНГ удельный вес теневой экономики значительно выше: в Туркменистане - $14 \%$ от ВВП, в Казахстане - 27\%, в Армении - 29\%, в Молдавии - 31\% [15]. В развивающихся странах соответствующий показатель достигает $40-45 \%$.

По официальным данным статистических органов Российской Федерации в теневом секторе задействовано около 40\% трудоспособного населения страны, то есть - 30 млн российских граждан, на неё же приходится 20\% ВВП (по неофициальным данным в два раза больше). Во многих регионах Российской Федерации, в особенности в регионах Северо-Кавказского Федерального округа, эти показатели значительно выше. Так, по данным исследований проведенных дагестанскими учеными, в Республике Дагестан теневая экономика достигает 60\% ВВП [1].

В России основы теневой экономики были заложены еще в советское время в связи с дефицитом ряда товаров (в особенности, зарубежного производства). В процессе ускоренного развития рыночной экономики РФ возник дефицит зако- на, который стал питательной средой для роста масштабов теневой экономики. На современном этапе деструктивное влияние теневой деятельности на развитие экономики сохраняется, вызывает нарастающую межрегиональную социально - экономическую дифференциация и рост угрозы безопасности государства. Теневая экономика образуется, прежде всего, из-за существования условий, при которых становится выгодно скрывать свою экономическую деятельность от широкого круга лиц.

Различные оценки масштабов теневой экономики обуславливают необходимость исследования и анализа методов ее определения. Различают прямые и косвенные методы оценки теневой экономики. Прямые методы предполагают использование специальных обследований, опросов или налоговых аудиторских проверок и других соответствующих методов для выявления расхождений между доходами и расходами и для характеристики отдельных аспектов теневой деятельности по группам налогоплательщиков. Наибольшее распространение среди прямых методов получили выборочные обследования в виде опроса, используются во многих европейских странах, в частности в Норвегии [8].К неудобствам этих методов относятся недостатки опросов. Например, средняя точность и результаты зависят от готовности респондента сотрудничать и давать объективную и достоверную информацию. Оценки теневой экономики могут также базироваться на несоответствии между доходом, объявленным для налогообложения, и тем, который рассчитан при выборочных проверках. Особенно эффективны в таком случае налоговые аудиторские проверки. Поскольку эти проверки предназначены для измерения количества необъявленного налогового дохода, то они могут также использоваться для расчета теневой экономики. Однако при таком методе, основанном на смещенной выборке, возможны неточности. Другим неудобством названных методов (опросы и налоговая ревизия) является невозможность охватить все теневые действия, поэтому они могут представлять собой нижнюю границу оценок. В то же время, следует отметить, что они позволяют обеспечивать детальную информацию о теневых экономических действиях, структуре и составе тех, кто работает в теневой экономике [14]. 
На макроуровне для измерения теневой экономики используются косвенные методы, основанные, прежде всего, на показателях официальной статистики, данных правоохранительных, кредитных, налоговых и финансовых органов. При этом, оценки теневой экономики осуществляется с использованием таких методов, как: сравнение доходов и расходов, метод, основанный на расчетах показателей занятости («итальянский» метод), монетарный, технологических коэффициентов, экспертный, структурный, мягкого моделирования (оценки детерминантов). Метод сравнения доходов и расходов основан на предположении, что превышение расходов над доходами, являются индикатором «теневой» экономики. Сведения о фактических доходах, получают, как правило, из информации об уплаченных налогах платежей, а о расходах - в результате обследований деятельности организаций, индивидуальных предпринимателей и домохозяйств.

На расчетах показателей занятости, основан «итальянский» метод (разработан и применяется в Италии и других в зарубежных странах). Оценка теневой экономики «итальянским» методом заключается в том, что статистики определяют численность заполненных рабочих мест с использованием данных переписей, регулярной статистической, налоговой и социальной отчетности, на основании которой оценивается численность занятых в эквиваленте полной занятости. Достоинство такого подхода состоит в том, что людям, которых не спрашивают о доходах, нет смысла скрывать информацию об их рабочем времени. У «итальянского» метода также существуют ограничения для использования (высокая мобильность населения). Монетарные методы основаны на использовании такой особенности нелегальной экономики как предпочтение, отдаваемое наличным деньгам при совершении сделок (в нелегальной экономике в качестве средства платежа используются в основном наличные деньги). Метод технологических коэффициентов представляет собой примерное определение объемов производства товаров (работ, услуг) на основе наблюдений за производством и потреблением электроэнергии, воды, перевозок грузов транспортом и других косвенных показателей, поддающихся достаточ- но простому учету, для сравнения полученных данных с официальными. Структурный метод оценки «теневой» экономики основан на использовании информации о ее размерах в различных секторах экономики, сравнением «отраслевых» оценок по доле этих секторов в ВВП. [10].

Наличие множества методов свидетельствует о сложности оценки теневой составляющей экономики и весьма условных границах достоверности результатов при использовании одного метода. Прямые методы дают, как правило, дают заниженную оценку теневой экономики; косвенные - завышенную. Наиболее объективная оценка теневой экономики возможна при комплексном использовании различных методов. Следует отметить, что при анализе теневой экономики необходимо пользоваться методами не только экономики и социологии, но и других наук. Комплексный междисциплинарный подход позволяет наиболее объективно анализировать корни теневой экономики и оценивать ее масштабность.

Как было отмечено выше, в целом по Российской Федерации, на долю теневого сектора экономики приходится около $20 \%$ ВВП. Отдельные экспертные оценки часто в расчеты включают незаконную экономическую деятельность и называют цифры 2-3 раза превышающие официальные. Данный подход, на наш взгляд, является неверным, поскольку незаконная (подпольная) экономическая деятельность не является резервом формирования доходов бюджета. Такая экономическая деятельность подлежит устранению, а не легализации. При прямом расчете потерь бюджета необходимо учитывать все легально разрешенные виды экономической деятельности, в рамках которых имеют место не учитываемые официальной статистикой в процессе налогообложения производство товаров (работ, услуг).В то же время следует констатировать, что теневая экономическая деятельность, подлежащая легализации, в республиках СКФО, в том числе и в Республике Дагестан, имеет значительно более широкие масштабы, относительно других регионов Российской Федерации. По мнению директора Института социальноэкономических исследований ДНЦ РАН, д.э.н., проф. С. Дохоляна, в современных условиях отсутствуют эффективные методики, которые 


\section{Налоги и налогообложение 10(148) • 2016}

давали бы возможность оценить, насколько то или иное предприятие находится в «тени», кроме проведения ревизий непосредственно на местах. Есть технологии, позволяющие в определённой степени оценивать теневую экономику в масштабах страны или региона, но для предприятий они непригодны [16].

Эффективность налоговой политики можно определить коэффициентом налоговой безопасности, применительно к регионам - коэффициентом региональной налоговой безопасности (способность налоговой системы за счет стабильного и эффективного поступления налогов в бюджет обеспечить удовлетворение растущих общественных потребностей).

Необходимо различать коэффициент региональной налоговой безопасности как фактическое и реальное значение. Коэффициенты региональной налоговой безопасности дают оценку фактически сложившегося и потенциально возможного уровня налоговой самообеспеченности региона. Отношение всех налоговых поступлений мобилизуемые с территории конкретного субъекта РФ к расходной части консолидированного бюджета, изучаемого региона определим, как фактический коэффициент региональной налоговой безопасности. Учитывая тот факт, что Россия - федеративное государство, основываясь на принципах налогового федерализма (ключевым из которых является принцип самостоятельности бюджетов), необходимо ввести и такое понятие как «коэффициент реальной налоговой безопасности региона» (за основу расчета, которого следует брать лишь те налоговые поступления, мобилизуемые в консолидированный бюджет региона).

Расчеты показывают, что фактически сложившейся уровень региональной безопасности РД в 2015 г. составил 0,48\%. Данное значение свидетельствует об уровне дотационной регионального бюджета. Значение коэффициента реальной региональной налоговой безопасности уступает значению коэффициента фактической региональной безопасности на 6\% (2015 г.). Проведенное автором исследование свидетельствуют о низком уровне налоговой безопасности Республики Дагестан, следовательно, неспособности не только за счет собственных поступлений, но и за счет всех налоговых поступ- лений мобилизуемых с территории, обеспечить потребности региона. Причин низкого уровня названных коэффициентов в регионе несколько. К наиболее значимым относятся: факторы, влияющие на величину налоговых поступлений (наличие теневого сектора экономики, низкий уровень налоговой культуры населения, невысокий уровень рентабельности экономики и т.д.) и факторы, обуславливающие неэффективность и рост расходов регионального бюджета.

Проведенные расчеты по оценке бюджетных потерь в связи с теневой деятельностью, отраженные в таблице 1 , показывают, что в целом по Российской Федерации в бюджетную систему недопоступает налоговых доходов свыше 3,5\% ВВП, что за 2014 г. составило 2,54 трлн. руб. и это, без учета страховых взносов во внебюджетные социальные фонды, администрирование которых, не входит полномочия Федеральной налоговой службы (ФНС) России. В бюджетную систему Республики Дагестан, в связи с масштабностью теневой деятельности ежегодно недопоступает около 4\% ВРП или свыше 17 млрд. руб. налоговых доходов (без учета страховых взносов во внебюджетные социальные фонды). Учитывая неустойчивую ситуацию в экономики (несмотря на некоторые признаки ее смягчения) потери для российского бюджета, а также бюджетов субъектов Федерации, представляются значимыми. В этой связи, необходим системный подход для реализации комплекса мероприятий, направленных на снижение масштабов теневой деятельности и ее негативного влияния на различные институты государства, в том числе на бюджетную систему РФ и ее регионов.

Официальный уровень налоговой нагрузки (отношение фактически собранных налогов к валовому региональному продукту (ВРП)) в Республике Дагестане составляет менее 7\% (2013 г. - 6,1\%, в 2014 г.- 6,4\%, а в 2015 - 6,5\%). Для сравнения: по Северному Кавказу - свыше 10,6\%, по Российской Федерации, без учета страховых взносов во внебюджетные социальные фонды, около 18\%, (табл. 1). Учитывая, тот факт, что более 70\% расходных обязательств республиканского бюджета Республики Дагестан покрываются за счет безвозмездных поступлений из федерального бюджета данная ситуация является для региона не допустимой. По авто- 

Оценка выпадающих налоговых доходов консолидированного бюджета РФ,
в связи с теневой деятельностью субъектов экономики за 2012-2014 г.

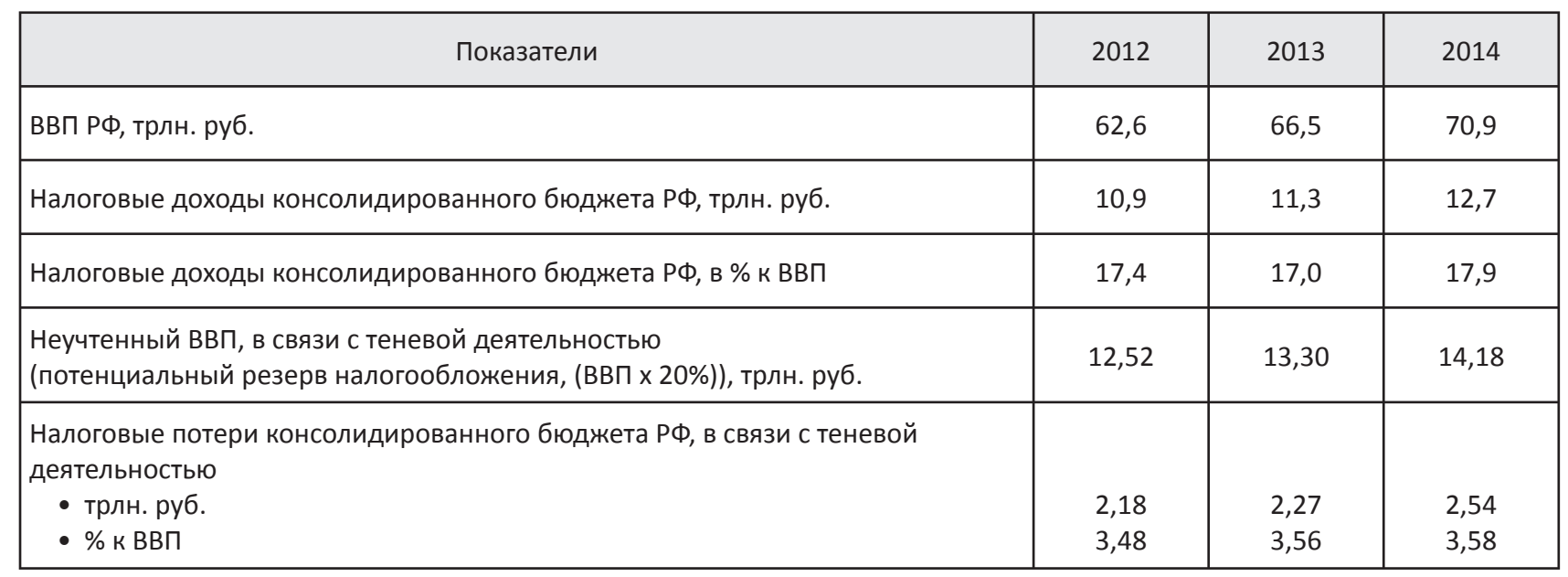

* Расчеты автора по официальным данным Федеральной службы государственной статистики России (2015). Доходы консолидированного бюджета РФ приводятся без учета страховых взносов во внебюджетные социальные фонды. www.gks.ru

рским расчетам, учет всех доходов республики, образующих ВРП позволило бы снизить безвозмездные трансферты из федерального бюджета почти в 2 раза.

На современном этапе необходима система реальных мер по легализации теневого сектора, прежде всего, для эффективного управления социальным и экономическим развитием, роста инвестиционной активности региона, обеспечения занятости, повышения жизненного уровня граждан, наиболее полной реализации человеческого потенциала и на этой основе, расширения налоговой базы. Помимо желания получить дополнительную прибыль, причинами теневой деятельности следует признать объективно существующие финансово-экономические трудности современного положения региона, которые заставляют субъектов хозяйствования уклоняться от уплаты налогов для того, чтобы сохранить свое дело. Анализ информации органов правоохранительных, статистических и фискальных органов о формах теневой деятельности в Дагестане, позволило нам сделать вывод, что в основе объективно существующих причин лежит нарушение личных экономических интересов субъектов экономики. Основная привлекатель- ность теневой сферы заключается в легкости доступа к предпринимательской активности и возможности наиболее полно удовлетворить в ней личные экономические интересы. Здесь имеется большой экономический и налоговый потенциал, который можно, поддержав, использовать на пользу региона и государства в целом.

Отношения бизнеса и власти, построенные на принципах взаимного доверия и удовлетворения экономических интересов, как отдельной личности, так и государства, реализуется во многих развитых зарубежных странах (Германии, Австрии, Норвегии), из стран постсоветского пространства - в Казахстане и приносит позитивные результаты в виде развития приоритетных отраслей экономики и возвращения части неформальной экономики в легальное русло. Об этом свидетельствуют как рост производства в базовых отраслях экономики, так и рост налоговых поступлений в ВВП, которые произошли на фоне значительного снижения налоговой нагрузки для конкретных субъектов экономики. Пример Республики Казахстан, заключающийся в упрощении регистрации субъектов экономической деятельности, взимание налогов по заявленной налоговой базе, снижение налоговой нагрузки 


\section{Налоги и налогообложение 10(148) • 2016}

в приоритетных отраслях экономики при одновременном совершенствовании налогового администрирования, целесообразно было бы использовать и в регионах РФ, в том числе и в Республике Дагестан, где высокий уровень теневого сектора не удается снизить традиционными методами [13].

Реализация заявительного принципа позволяет нивелировать бюрократические преграды и облегчает доступ в легальную сферу хозяйственной деятельности. Такой подход также способствует вовлечению в экономику личных материальных ресурсов, тем самым частично решая проблему финансирования инвестиционной деятельности. Однако личных ресурсов населения Республики Дагестан, для которого характерен один из самых низких уровней жизни в РФ, может оказаться недостаточно. Поэтому необходимо создать механизм государственной поддержки инвестирования в легальную экономику. На региональном уровне возможно кредитование инновационной деятельности из бюджетов разных уровней по накопительному принципу. В процессе реализации данного подхода государство получает законопослушного налогоплательщика, который становится сам себе инвестором и гарантом.

Анализ проявления теневой экономики в субъектах Российской Федерации позволяет выявить ряд специфических черт ее проявления, обусловленных во многом социально-экономической структурой того или иного региона. В Москве и Санкт-Петербурге это преимущественно кредитно-финансовая сфера и операции с недвижимостью. Во многих территориях они связаны с экспортно-ориентированным сырьевым производством: Якутия (алмазы, золото), Тюменская область (нефть), Кемеровская область (уголь), и др.

В портовых и приграничных городах (Владивосток, Хабаровск, Новороссийск, Мурманск, Калининград), теневая экономика в основном связана с незаконным рыбным промыслом и махинациями с имуществом судоходных компаний. Так, по официальным данным, Калининградская область существенно отстает в среднем по субъектам РФ по объемам инвестиций в основной капитал (в 2 раза), уровню жизни населения (в 1,4 раза), по величине валового продукта на душу населения - в 1,5 раза [18]. В то же время в данной области наблюдается активное строительство элитного жилья, работают дорогие магазины, рестораны и т.п. Все это свидетельствует о том, что официальные и реальные доходы калининградцев сильно различаются. По разным оценкам, теневой сектор в регионе занимает 40-60\% внутреннего регионального продукта.

Специфическими чертами теневой деятельности, присущих Республике Дагестан являются: вовлеченность в теневую экономику всех слоев населения республики от рабочих до политиков; реализация личных экономических интересов в рамках национальных кланов; преобладание этнических интересов над общими государственными интересами. Минимальные оценки различных Министерств и ведомств Республики Дагестан свидетельствуют, о значительных резервах роста налогового потенциала региона. Наиболее низкая налоговая нагрузка наблюдается в сфере общественного питания, причем имеют место потери как по налогу на доходы физических лиц, так и по упрощенной системе налогообложения. Например, в Махачкале на 1.01.2015 г. числилось 60 ресторанов, в расчете на один ресторан приходится 90 тысяч рублей уплаченных налогов в год, то есть 7,5 тысяч рублей в месяц, что не отражает реальную картину. В 2015 г. налоговые поступления в бюджетную систему РД в разрезе основных видов деятельности на одного занятого (15,6 тыс. руб.) были почти в 2,6 раза меньше аналогичного показателя по Ставропольскому краю (40,5 тыс. руб.), и почти в 2 раза меньше показателей по Республике Ингушетия (29,6 тыс. руб.) [20]. Но при этом по обороту малых предприятий Республика Дагестан занимает лидирующие позиции в СКФО - 137,6 млрд. руб. Аналогичный показатель по Кабардино-Балкарской Республике - 27,9 млрд. рублей, или в 5 раз меньше. При этом налогов по данному виду деятельности в РД поступило 708 млн. руб., а в Кабардино-Балкарской Республике - 608млн. руб. Аналогичная ситуация наблюдается по отрасли «строительство». В структуре строительно-монтажных работ не менее $30 \%$ затрат приходится на фонд оплаты труда. По данной отрасли только налога на доходы физических лиц должно было поступить, сучетом всевозможных 
вычетов, более 2 млрд. руб., фактически поступает в почти в 4раза меньше.

Во многом данная практика вызвана с широким распространением в Дагестане различных схем ухода от налогов, в том числе выплатой «теневой» заработной платы в «конвертах», а также низким уровнем налоговой грамотности населения. В многих отраслях экономики (в особенности в строительстве) большинство работников работаю без заключения трудового договора, что выводит доходы данной категории лиц из-под обложения НДФЛ. Эти сложности могут быть решены налоговыми органами посредством проведения проверок организаций, имеющих признаки выплаты «серой» зарплаты, выявление организаций, не заключающих с работниками трудовых или гражданско-правовых договоров, а так же организаций, в которых официальная заработная плата работников ниже среднеотраслевого уровня. Так же при осуществлении контрольных мероприятий в отношении физических лиц эффективным является использование информации из внешних источников, прежде всего о владельцах транспортных средств и собственниках имущества (метод технологических коэффициентов).

Во многих регионах РФ, кроме заработной платы, другие виды доходов в большинстве случаев ускользают от налогообложения. Об этом свидетельствуют данные как о структуре начисленной налоговой базы по налога на доходы физических лиц, так и о составе реальных плательщиков налога на доходы физических лиц. Так, к примеру, в 2015 г., в среднем по всем субъектам РФ отчетные данные ФНС России, свидетельствуют, что наибольшую долю (95,3\%) в налоговой базе занимают доходы, облагаемые по ставке 13\% [18]. Аналогичная ситуация наблюдается и в Дагестане. Так, регион в структуре денежных доходов населения, имеет самый низкий показатель среди субъектов РФ по уровню официальной зарплаты, и самый высокий по «прочим доходам». Весьма низкие налоговые поступления от других видов доходов физических лиц, за исключением заработной платы, свидетельствует о недоиспользовании потенциала налога на доходы физических лиц

Не значительный объем поступлений НДФЛ с не зарплатных доходов может быть следствием, как налоговой неграмотности населения, так и умышленного уклонением от уплаты налога на доходы физических лиц. В этой связи меры по усилению налогового администрирования и ответственности налогоплательщиков за уклонение от уплаты налога, должны реализовываться вкупе с мерами направленными как повышение доверия к государственному институту, обеспечения прозрачности и эффективности бюджетных расходов, так и повышения финансовой грамотности и на этой основе воспитания налоговой культуры населения. Налоговую культуру вообще следует рассматривать как неотъемлемую часть экономической и правовой культуры населения.

Значительные недоиспользованные налоговые резервы имеются в сфере малого бизнеса. Почти 2/3 малых организаций республики Дагестан не зарегистрированы и функционируют в качестве теневого бизнеса. Количественные и финансовые данные по сектору малого предпринимательства владельцами предприятий занижаются или скрываются. Поэтому только небольшая часть реального количества малых предприятий в сфере малого бизнеса находит отражение в статистических данных по Республике Дагестан [7].

Как известно, в зарубежных странах малый бизнес играет важную роль в решении проблем безработицы и повышения занятости населения. В субъектах Российской Федерации, в особенности в Чеченской Республике, Ингушетии, Калмыкии и в Республике Дагестан роль малых организаций в обеспечении занятости населения остается незначительной [3]. В Дагестане она составляла в 2015 г. - 6,5\%, а в целом по РФ - 12,2\%. В настоящее время использование потенциала малого и среднего бизнеса также может увеличить налоговые поступления в региональные и местные бюджеты, поскольку развитие предпринимательства, увеличивает число новых рабочих мест и жизненный уровень населения региона.

Одним из сложных к выявлению и противодействию видов уклонения от уплаты налогов во многих регионах РФ являются налоговые преступления, совершаемые при участии сформировавшихся в начале 2000-х годов крупных многоотраслевых холдингов под контролем 


\section{Налоги и налогообложение 10(148) • 2016}

которых в совокупности с естественными монополиями находиться не менее 40-50\% всех финансовых потоков страны, при этом ими же обеспечивается значительная часть налогов и иных платежей в бюджет [6].

В результате предоставления налоговых льгот государство и субъекты РФ недополучает по различным оценкам от 45 до 55\% всех администрируемых ФНС России налоговых платежей. В этой связи, как отмечалось в проведенных ранее исследованиях автора, важным направлением реформирования налоговой системы является ликвидация льгот, не оправдывающие с точки зрения социально-экономической эффективности, но при этом дающие значительные преимущества отдельным налогоплательщикам и возможности для уклонения от уплаты налогов и роста теневой экономики Однако, отказ льгот, также как и процесс ведения новых льгот, должен сопровождаться их предварительной экспертизой о пользе и целесообразности [12].

Ключевым направлением совершенствования налогового администрирования является внедрение в практику новых, основанных на передовых информационных технологиях, форм и методов налогового контроля. Одной их глобальных проблем российских регионов - существование фирм, создающих на короткое время и уклоняющих от налогов. Вследствие свободного выбора места регистрации деятельности субъектами экономики, налоговые органы не всегда могут осуществлять контроль за их деятельностью. В сложившейся ситуации целесообразно ввести поправку в Налоговый кодекс РФ: предусмотреть обязательный порядок регистрации субъектов экономики по месту их фактической деятельности.

Проведенное нами исследование по анализу теневой деятельности, ее деструктивного влияния на социально - экономическое развитие и возможных путях снижения позволило нам сделать следующие выводы и предложить ряд рекомендаций. В частности, необходима:

- Объективна оценка масштабов теневой деятельности. В практике разных государств используются различные методы оценки теневой экономики (которые проанализированы в данном исследовании), каждый их них имеет как достоинства, так и отдельные недостатки. Наиболее объективная оценка теневой экономической деятельности возможна только при комплексном использовании различных методов;

- Реализация нового подхода к решению проблем ограничения масштабов теневой деятельности в Российской Федерации. Во многом он должен определяться интеграцией между теневой и легальной экономикой. Она предусматривает формирование условий, которые стали бы невыгодными для теневого бизнеса, на основе совершенствование правового и налогового законодательства в направлении стимулирования развития предпринимательства и развития человеческого капитала, разработку и реализацию эффективных мер защиты населения со стороны государства от финансового мошенничества, обеспечение защищенности их сбережений;

- $\quad$ целью повышения эффективности противодействия теневой экономике необходимо провести значимые изменения в макроэкономической политике, направленной на переход не к валовому росту инвестиций, а к росту эффективных инвестиций, создающих конкурентоспособное производство. Необходимо обеспечить прозрачность, повысить эффективность и качество бюджетных расходов как фактора преодоления психологических причин проблем со сбором налоговых платежей в бюджетную систему, которые лежат в плоскости недоверия налогоплательщиков к проводимой государством политике. Однако, следует признать, что полностью ликвидировать теневой бизнес не возможно. Ориентировочным параметром может быть удельный вес теневой экономики, не превышающий 10\% ВВП. Опыт индустриальных стран показывает допустимость такого уровня теневой экономики. Сокращение теневой экономической деятельности до 10\% должно быть выдвинуто в качестве стратегической задачи РФ на современном этапе социально -экономического развития. В качестве важного пути возвращения теневой деятельности в легальный сектор экономики субъектов Федерации, следует выделить необходимость более 
полного учета экономических интересов личности (с учетом специфики региона), поскольку потенциал предпринимательской деятельности субъектов экономики может быть использован в интересах государства, если в результате такой деятельности личность сможет получать выгоду, достаточную для своего развития.

- Меры по наиболее полному учета экономических интересов личности должны сопровождаться совершенствованием форм и методов организации налогового администрирования, широкого использования механизмов межведомственного взаимодействия налоговых администраторов с другими органами исполнительной власти, создания системы сплошного контроля, владения, управления и движения собственности, финансовых активов и доходов как основы противодействия налоговым правонарушениям. Необходимо повысить уровень использования в организации налогового контроля альтернативных (косвенных) методов определения налоговой базы на основании сведений, получаемых от организаций, взаимодействующих с налогоплательщиком. Совершенствование форм и методов организации налогового администрирования, с учетом изучения наиболее прогрессивных элементов богатого опыта зарубежных стран организации налогового контроля, создать основу для роста собираемости налогов, финансовой независимости регионов и роста безопасности государства.
- Работа правоохранительных органов по борьбе с теневой экономикой, на наш взгляд, должна строиться по отраслевому и территориальному принципам. Отраслевой принцип предполагает создание в структуре правоохранительных органов подразделений, специализирующихся на выявлении и расследовании правонарушений в различных отраслях экономики. Применение территориального принципа дает возможность учесть региональные условия хозяйствования, позволяет сконцентрировать внимание правоохранительных органов на наиболее опасных видах теневой экономической деятельности в той или иной местности. При этом, ключевую роль в борьбе с теневой экономикой должны играть не силовые действия правоохранительных органов, а саморазвитие и сознательное конструирование неформальных институтов, отрицающих теневую экономику.

- Необходима государственная поддержка по продвижению и реализации инвестиционных проектов, осуществляемых организациями, в сфере промышленности. К примеру, промышленность Дагестана составляет в структуре ВРП региона всего 6\%, а налоговые поступления с данного сектора экономики - свыше 30\%. Поддерживая промышленные организации, можно повысить уровень собственных доходов регионального бюджета, обеспечить общий экономический рост и безопасность субъекта Федерации.

\section{Работа выполнена в рамках в рамках реализации государственного задания Министерства образования и науки \# 2014/33 Минобрнауки России в сфере научной деятельности «Комплексное исследование противодействия идеологии экстремизма и терроризма в Дагестане».}

\section{Библиография}

1. Ахмедуев А.Ш. Теневая экономика: системный ресурс и фактор торможения социально-экономического развития. // Вопросы экономи-ки.2015-№9.-c.152.-160. http://elibrary.ru/item. asp?id=24146954.

2. Барсукова С.Ю. Сращивание теневой экономики и теневой политики. // Мир России. 2006. T. XV.№3.-c. 34-40. 


\section{Налоги и налогообложение 10(148) • 2016}

3. Буров В.Ю., Определение масштабов теневой экономики. // Вестник экономиста. 2012.-№4. http:// vseup.ru/static/articles/Burov_2.pdf.

4. Волков В.В. Силовое предпринимательство: экономико-социологический анализ. -М.: ГУ-ВШЭ, 2005. $-345 c$.

5. Guttmann, P.M. (1977).The Subterranean Economy.// Financial Analysts Journal, 33, pp. 24-27.

6. Ермакова Е.А. Теория и методология государственного налогового менеджмента. Саратов: СГСЭу, 2007.-347c.

7. Иманшапиева М.М. Легализация теневого сектора экономики как фактор повышения экономической активности регионов (по материалам Республики Дагестан). //Финансы и кредит. 2013-№31 (559). - c. 61-68. http://elibrary.ru/item.asp?id=20174712.

8. Isachsen A., Strom S. The size and growth of the hidden economy in Norway // Review of Income and Wealth. 1985.-31/1. P. 21-38. DOI: 10.1111/j.1475-4991.1985.tb00496

9. Каценелинбойген А. Цветные рынки в Советском Союзе. // Экономическая теория преступлений и наказаний. Реферат, журнал. №4. Теневая экономика в советском и постсоветском обществах. Часть 2. Статьи. Библиография. -М.: РГГУ, 2002. -с.123.

10. Кормишкина Л.А. Теневая экономика: учеб, пособие для ву-зов / Л. А. Кормишкина, О. М. Лизина. - Саранск: Изд-во Мордов, ун-та, 2009. -136 с. еconomic.social/teoriya.../tenevaya-ekonomika-uchebposobie-dlya-vuzov.html.

11. L'économie informally-Cairn.info (2011). www//.cairn.info/revue-etudes-economiques-de-l-ocde2011.

12. Musaeva Khaibat Magomedtagirovna, Aliev Basir Khabibovich, Suleymanov Magomed Magomedovich, Dyukina.Tatiana Olegovna. Tax re-lieves: Costs of their application in taxation and issues of the efficiency evaluation (2015). //Asian Social Science.Vol.11.-№7. http://dx.doi.org/10.5539/ass.v11n5p333.

13. Мусаева Х.М., Лаченилаева М.А. Влияние теневой экономики на налоговую составляющую региона и резервы роста налоговых доходов (по материалам Республики Дагестан). //Экономика и предприниматель-ство.2015-№12-2. - с. 474-477.

14. Перов Е.В. Оценка теневой экономики России. Экономическая безопасность. // Управление экономическими системами. 2015-№3. uecs.ru/marketing/item/3395-2015-03-10-11-16-16.

15. Теневая экономика в субъектах СКФО. Фонд перспективных исследований «Бастион». - М., 2012.-с.57-89.

16. Теневая экономика Дагестана: ....размер имеет значение.// Черновик. 2015-02-20 №07.

17. Олсон М. Рассредоточение власти и общество в переходный период. Лекарства от коррупции, распада и замедления темпов экономического роста // Экономика и математические методы. 1995. Т. 31.-Вып. 4.

18. Федеральная служба государственной статистики (2016). [Офиц. Сайт], http:// www.gks.ru.

19. Федеральная Налоговая служба (2016). [Офиц. Сайт], http:// www.nalog.ru.

20. Федеральной службы государственной статистики по Республике Дагестан (2016). [Офиц. Сайт]. www://dagstat.gks.ru/.

21. Королева Л.П., Танякина О.А. Оценка угроз налоговой безопасности РФ по индикаторам налоговых доходов консолиди рованного бюджета // Национальная безопасность / nota bene. - 2016. - 2 . - C. 266 - 275. DOI: 10.7256/2073-8560.2016.2.15573.

\section{References (transliterated)}

1. Akhmeduev A.Sh. Tenevaya ekonomika: sistemnyi resurs i faktor tormozheniya sotsial'noekonomicheskogo razvitiya. // Voprosy ekonomi-ki.2015-№9.-s.152.-160. http://elibrary.ru/item. asp?id=24146954.

2. Barsukova S.Yu. Srashchivanie tenevoi ekonomiki i tenevoi po-litiki. // Mir Rossii. 2006. T. XV.-№3.-s. $34-40$. 
3. Burov V.Yu., Opredelenie masshtabov tenevoi ekonomiki. // Vestnik ekonomista. 2012.-№4. http://vseup. ru/static/articles/Burov_2.pdf.

4. Volkov V.V. Silovoe predprinimatel'stvo: ekonomiko-sotsiologicheskii analiz.-M.: GU-VShE, 2005.-345s.

5. Guttmann, P.M. (1977).The Subterranean Economy.// Financial Analysts Journal, 33, pp. 24-27.

6. Ermakova E.A. Teoriya i metodologiya gosudarstvennogo nalo-govogo menedzhmenta. Saratov: SGSEU, 2007.-347s.

7. Imanshapieva M.M. Legalizatsiya tenevogo sektora ekonomiki kak faktor povysheniya ekonomicheskoi aktivnosti regionov (po materia-lam Respubliki Dagestan). //Finansy i kredit. 2013-№31 (559). - s. 6168. http://elibrary.ru/item.asp?id=20174712.

8. Isachsen A., Strom S. The size and growth of the hidden economy in Norway // Review of Income and Wealth. 1985.-31/1. R. 21-38. DOI: 10.1111/j.1475-4991.1985.tb00496

9. Katsenelinboigen A. Tsvetnye rynki v Sovetskom Soyuze. // Ekonomicheskaya teoriya prestuplenii i nakazanii. Referat, zhurnal. №4. Tenevaya ekonomika v sovetskom i postsovetskom obshchestvakh. Chast' 2. Sta-t'i. Bibliografiya.-M.: RGGU, 2002.-s.123.

10. Kormishkina L.A. Tenevaya ekonomika: ucheb, posobie dlya vu-zov / L. A. Kormishkina, O. M. Lizina. - Saransk: Izd-vo Mordov, un-ta, 2009. -136 s. economic.social/teoriya.../tenevaya-ekonomika-uchebposobie-dlya-vuzov.html.

11. L'économie informally-Cairn.info (2011). www//.cairn.info/revue-etudes-economiques-de-l-ocde2011.

12. Musaeva Khaibat Magomedtagirovna, Aliev Basir Khabibovich, Suleymanov Magomed Magomedovich, Dyukina.Tatiana Olegovna. Tax re-lieves: Costs of their application in taxation and issues of the efficiency evalua-tion (2015). //Asian Social Science.Vol.11.-№7. http://dx.doi.org/10.5539/ass.v11n5p333.

13. Musaeva Kh.M., Lachenilaeva M.A. Vliyanie tenevoi ekonomiki na nalogovuyu sostavlyayushchuyu regiona i rezervy rosta nalogovykh dokhodov (po materialam Respubliki Dagestan). //Ekonomika i predprinimatel'-stvo.2015-№12-2. - s. 474-477.

14. Perov E.V. Otsenka tenevoi ekonomiki Rossii. Ekonomicheskaya bezopasnost'. // Upravlenie ekonomicheskimi sistemami. 2015-№3. uecs.ru/marketing/item/3395-2015-03-10-11-16-16.

15. Tenevaya ekonomika v sub"ektakh SKFO. Fond perspektivnykh issledovanii «Bastion». - M., 2012.-s.57-89.

16. Tenevaya ekonomika Dagestana: ....razmer imeet znachenie.// Cher-novik. 2015-02-20 №07.

17. Olson M. Rassredotochenie vlasti i obshchestvo v perekhodnyi period. Lekarstva ot korruptsii, raspada i zamedleniya tempov ekonomiche-skogo rosta // Ekonomika i matematicheskie metody. 1995. T. 31.Vyp. 4.

18. Federal'naya sluzhba gosudarstvennoi statistiki (2016). [Ofits. Sait], http:// www.gks.ru.

19. Federal'naya Nalogovaya sluzhba (2016). [Ofits. Sait], http:// www.nalog.ru.

20. Federal'noi sluzhby gosudarstvennoi statistiki po Respub-like Dagestan (2016). [Ofits. Sait]. www:// dagstat.gks.ru/.

21. Koroleva L.P., Tanyakina O.A. Otsenka ugroz nalogovoi bezopasnosti RF po indikatoram nalogovykh dokhodov konsolidirovannogo byudzheta // Natsional'naya bezopasnost' / nota bene. - 2016. - 2. - C. 266 - 275. DOI: 10.7256/2073-8560.2016.2.15573. 